\title{
Mechanical Behavior of Robocast Alumina
}

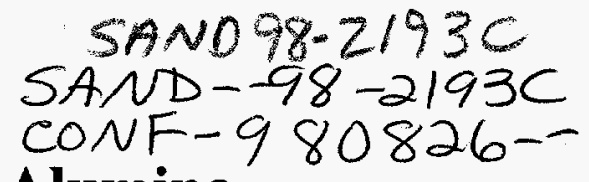

\author{
Hugh B. Denham, Joseph Cesarano III, Bruce H. King \\ Sandia National Laboratories \\ Paul Calvert \\ University of Arizona
}

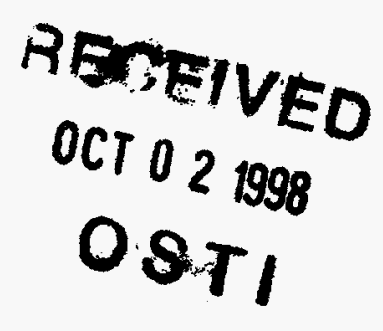

\begin{abstract}
Direct fabrication of alumina parts by robocasting was completed. This method is based on three-dimensional deposition of binderless aqueous alumina slurries. Parts were made with different deposition paths and mechanical testing performed to determine the effects of bead alignment. Properties were also compared to alumina processed more traditionally.
\end{abstract}

\section{Introduction}

Robocasting is a method of solid freeform fabrication of ceramic parts from aqueous slurries [1]. A computer controls the robotic deposition of highly concentrated colloidal slurries (Figure 1). The slurry is deposited from a syringe at a controlled rate in a layerwise process. Upon deposition, robocasting relies on a small amount of drying to induce a rheological transition of the slurry. The slurry changes from a flowable pseudo-plastic state to a solid-like dilatant mass. This transition gives each layer the strength necessary to support subsequent layers of freshly deposited slurry. Robocasting does not require polymerization reactions or wax crystallization. Only drying is necessary to build three-dimensional parts.

In order to make good parts via robocasting several issues must be balanced. High solids loadings are necessary, so powder surface chemistry and interparticle forces must be controlled. Pseudo-plastic rheology is needed to allow for flow through a small nozzle followed by enough strength to form a bead. The drying rate of the deposited beads is also critical to form ideal bead shapes. Bead knitting is also an issue; the beads must wet one another and flow enough so that there are no channels or voids between the beads. In addition to these materials issues are the parameters associated with the freeform process: table speeds, deposition rate, nozzle size and associated software.

The advantages of robocasting are many. The aqueous systems are binderless and have very low toxicity. A densified part can be made in less than 24 hours. The technique is amenable to multi-material fabrication. What is investigated here is the mechanical behavior of robocast parts with attention to the deposition paths used during fabrication.

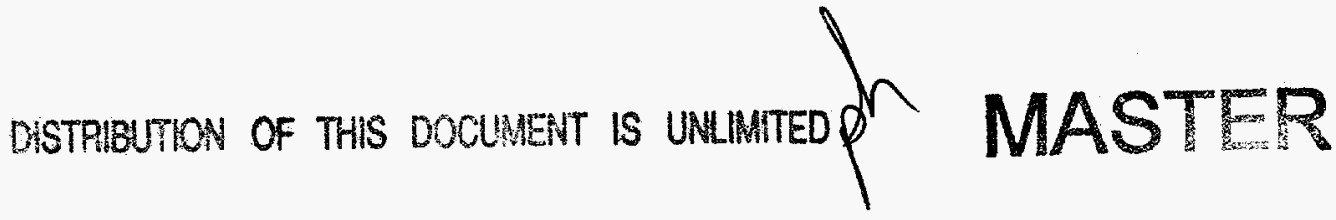




\section{DISCLAIMER}

This report was prepared as an account of work sponsored by an agency of the United States Government. Neither the United States Government nor any agency thereof, nor any of their employees, makes any warranty, express or implied, or assumes any legal liability or responsibility for the accuracy, completeness, or usefulness of any information, apparatus, product, or process disclosed, or represents that its use would not infringe privately owned rights. Reference herein to any specific commercial product, process, or service by trade name, trademark, manufacturer, or otherwise does not necessarily constitute or imply its endorsement, recommendation, or favoring by the United States Government or any agency thereof. The views and opinions of authors expressed herein do not necessarily state or reflect those of the United States Government or any agency thereof. 


\section{DISCLAIMER}

Portions of this document may be illegible in electronic image products. Images are produced from the best available original document. 


\section{Experimental}

Alumina bars were made for mechanical testing via four routes: uniaxial pressing, isostatic pressing, slip casting and robocasting. In addition, the robocast samples were made with different build patterns to investigate possible anisotropy due to bead alignment and inter-bead strength.

Alcoa A15 alumina powder was used in all samples. The surface area was $4.3 \mathrm{~m}^{2} / \mathrm{g}$ with an average particle size of $2.24 \mu \mathrm{m}$. The entire particle size distribution ranged from $10 \mu \mathrm{m}$ to $0.2 \mu \mathrm{m}$. Uniaxial pressed bars were made at $6 \mathrm{ksi}(41 \mathrm{MPa})$ in a Carver press. Isostatic pressed samples were first pressed uniaxially to $\sim 1.5 \mathrm{ksi}(10 \mathrm{MPa})$, followed by isostatic pressing to 25 ksi (172 MPa). No binders were used during pressing.

Slurry preparation for slip casting and robocasting was carried out using the alumina powder, water, and Darvan $821 \mathrm{~A}$ as a dispersant. The slip casting slurry was 40 volume percent solids, and was cast in a plaster mold. A simple box shaped mold was used, with the walls being removed in the green state yielding a flat slab for cutting into test bars. Bars were only cut from regions near the center of the flat slab as to insure a sample set that was cast uniformly.

For the robocast samples, a 60 -volume percent solids aqueous slurry was used. The slurry was ball milled slowly to allow mostly mixing and little milling. The slurry was mixed in this manner until the proper rheology was obtained (about 2 weeks). Extrusion was performed at a table speed of $8-10 \mathrm{~mm} / \mathrm{sec}$, with a $0.8347 \mathrm{~mm}$ diameter nozzle, and table temperature of $40^{\circ} \mathrm{C}$ (typical laboratory humidity is $20-40 \%$ ). Test bars were made with three different build patterns: a lengthwise writing pattern, a widthwise writing pattern, and a cross-hatch pattern alternating lengthwise and widthwise writing (Figure 2). These patterns were chosen to characterize the strength of the material when broken parallel to the bead direction (lengthwise build), perpendicular to the bead direction (widthwise build), and a combination of these (crosshatch build).

Densities were measured by Archimedes method, with green densities measured after bisque firing to $1050^{\circ} \mathrm{C}$. All parts were fired to $1650^{\circ} \mathrm{C}$ for 2 hours. Four-point bend specimens were machined to specifications for MIL-STD-1942b, by Chand Associates. Mechanical testing was performed on an Instron machine, with a crosshead speed of $0.5 \mathrm{~mm} / \mathrm{sec}$. There were 8 samples each from the pressing methods, 47 slip cast samples, and 10-12 samples from each of the different robocasting deposition patterns.

\section{Discussion}

The densities for the four processes are shown in Table 1. While the isostatic pressed bars yielded the highest fired density; the others were comparable. This demonstrates that robocasting produces sintered parts of similar density to other processing routes. A sintered density on the order of $94 \%$ is all that can be reasonably expected from unmilled A-15 powder. 
Table 1:

Percent of theoretical density for A15 alumina parts for various processing methods.

\begin{tabular}{|l|c|c|}
\hline & Green & Fired \\
\hline Uniaxial Pressed & 64.5 & 93.4 \\
\hline Isostatic Pressed & 69.3 & 95.2 \\
\hline Robocast & 68.4 & 93.7 \\
\hline Slip Cast & 71.3 & 93.0 \\
\hline
\end{tabular}

The flexural strengths from the 4-point bend tests are shown in Figure 3. It should be noted that these values are not as high as are often listed for high purity aluminas but the relative values are still useful for determining differences due to processing. These bars were made with Alcoa A15 alumina, which is not an optimal powder for making high strength parts. In addition, these parts were not sintered to theoretical density, and the surface finish on MIL-STD-1942b was a relatively rough 320-grit wheel. Regardless, as expected, the isostatic pressed bars performed better than the uniaxial pressed. The slurry based parts, slip cast and robocast, exhibited higher strengths than the pressed samples. The robocast parts varied in strength for different building paths, with the lengthwise fill having the same strength as the slip cast parts. Additionally, even the weakest robocast bars have strengths higher than isopressed bars. This shows that robocast parts can be made relatively strong when compared to parts fabricated more traditionally.

What is interesting is that the strength of the robocast parts is dependent on the build direction. The robocast lengthwise fill pattern shows strength $60 \mathrm{MPa}$ higher than the widthwise or crosshatch fill. That is, the strength parallel to the build direction is approximately $20 \%$ higher than the strength perpendicular to the build direction. This behavior in analogous to a fiber reinforced material and may be due to two effects. Flaws may develop when two beads are deposited side by side and/or residual stresses may develop between beads due to small density variations induced during drying and sintering. The average strength of the crosshatch build pattern is nearly the same as the widthwise build. This is not entirely surprising since the ultimate strength is most likely controlled by the weaker widthwise layers and the inherent toughness of the alumina is low. However, upon further examination of the crosshatch strength data a small but significant alignment effect was discovered and is discussed below.

What is interesting is that the strength of the robocast parts is dependent on the build direction. The robocast lengthwise fill pattern shows strength $60 \mathrm{MPa}$ higher than the widthwise or crosshatch fill. That is, the strength parallel to the build direction is approximately $20 \%$ higher than the strength perpendicular to the build direction. This behavior in analogous to a fiber reinforced material and may be due to two effects. Flaws may develop when two beads are deposited side by side and/or residual stresses may develop between beads due to small density variations induced during drying and sintering. The average strength of the crosshatch build pattern is nearly the same as the widthwise build. This is not entirely surprising since the ultimate strength is most likely controlled by the weaker widthwise layers and the inherent toughness of the alumina is low. However, upon further examination of the crosshatch strength data a small but significant alignment effect was discovered and is discussed below. 
Table 2:

Flexural strength in MPa for different orientations of slip cast and robocast alumina.

\begin{tabular}{|l|c|c|c|}
\hline & Top in Tension & Base in Tension & Standard Deviation \\
\hline Slip Cast & 309.80 & 288.67 & 40.3 \\
\hline Robocast Lengthwise & 301.89 & 310.21 & 27.6 \\
\hline Robocast Widthwise & 242.07 & 234.01 & 33.4 \\
\hline & & & Standard Deviation \\
\hline & $\begin{array}{c}\text { Lengthwise in } \\
\text { Tension }\end{array}$ & Widthwise in Tension & 37.1 \\
\hline Robocast Cross-Hatch & 256.64 & 225.09 & \\
\hline
\end{tabular}

When fracture surfaces of the robocast bars are examined some interesting features are revealed. Figure 4 shows the fracture surfaces for three robocast bars. The widthwise samples and cross-hatch samples show artifacts of the layerwise building process, while the lengthwise samples shows no remnants of the build path or layers. These textured surfaces show that there are preferential fracture paths parallel to the build direction. Therefore, the first inclination is to believe that defects were formed between beads during robocasting because of a lack of ample bead meshing during deposition. However, the micrographs in Fig. 5 may suggest an alternative explanation.

The micrographs in Figure 5 are of a part that was sectioned parallel to the build direction. At low magnification, the build pattern can still be barely discerned. At high magnification, pores and defects on the order of 4 to $10 \mu \mathrm{m}$ can be observed. Voids of this size are reasonable for unmilled A-15 alumina and are probably not due to robocasting defects. Also, the porosity present appears to be uniform both in the interior of beads and in the regions between the beads. Regardless of where micrographs are taken the microstructure is very similar to Fig. 5b. Why the microstructure appears uniform throughout the section while a clear texture reminiscent of the build pattern can be seen optically, remains a curiosity. The presence of residual stresses may be a possible explanation. Since robocasting relies on the drying of the deposited beads, uneven drying could lead to small density differences within each bead. If we consider a single deposited bead, drying occurs from the outside in. If the exposed surface dries too fast it would form a hard shell and the inside material may not be able to achieve the same density. A density difference within the part could lead to some residual stresses being built up during sintering.

\section{Conclusions}

We have shown that robocast alumina exhibits densities and strengths comparable to alumina processed more traditionally. However, the mechanical properties of robocast alumina are slightly anisotropic and dependent on the build path used. Strengths parallel to the build direction are nearly identical to slip cast parts. Strengths perpendicular to the build direction are slightly lower than the parallel strengths but higher than isostatically pressed parts. Also, when parts are broken in the proper orientation, preferential fracture paths may be observed that appear to mimic the layerwise build pattern. However, it is not yet clear if the preferential fracture paths 
are due to inadequate bead meshing or residual stress induced by nonuniform drying and sintering.

\section{Acknowledgment}

Sandia is a multiprogram laboratory operated by Sandia Corporation, a Lockheed Martin Company, for the United States Department of Energy under Contract DE-AC04-94AL85000.

\section{Reference}

1. J. Cesarano III, R. Segalman, and P. Calvert, "Robocasting Provides Moldless Fabrication from Slurry Deposition," Ceramic Industry, pp 94-102, April 1998. 


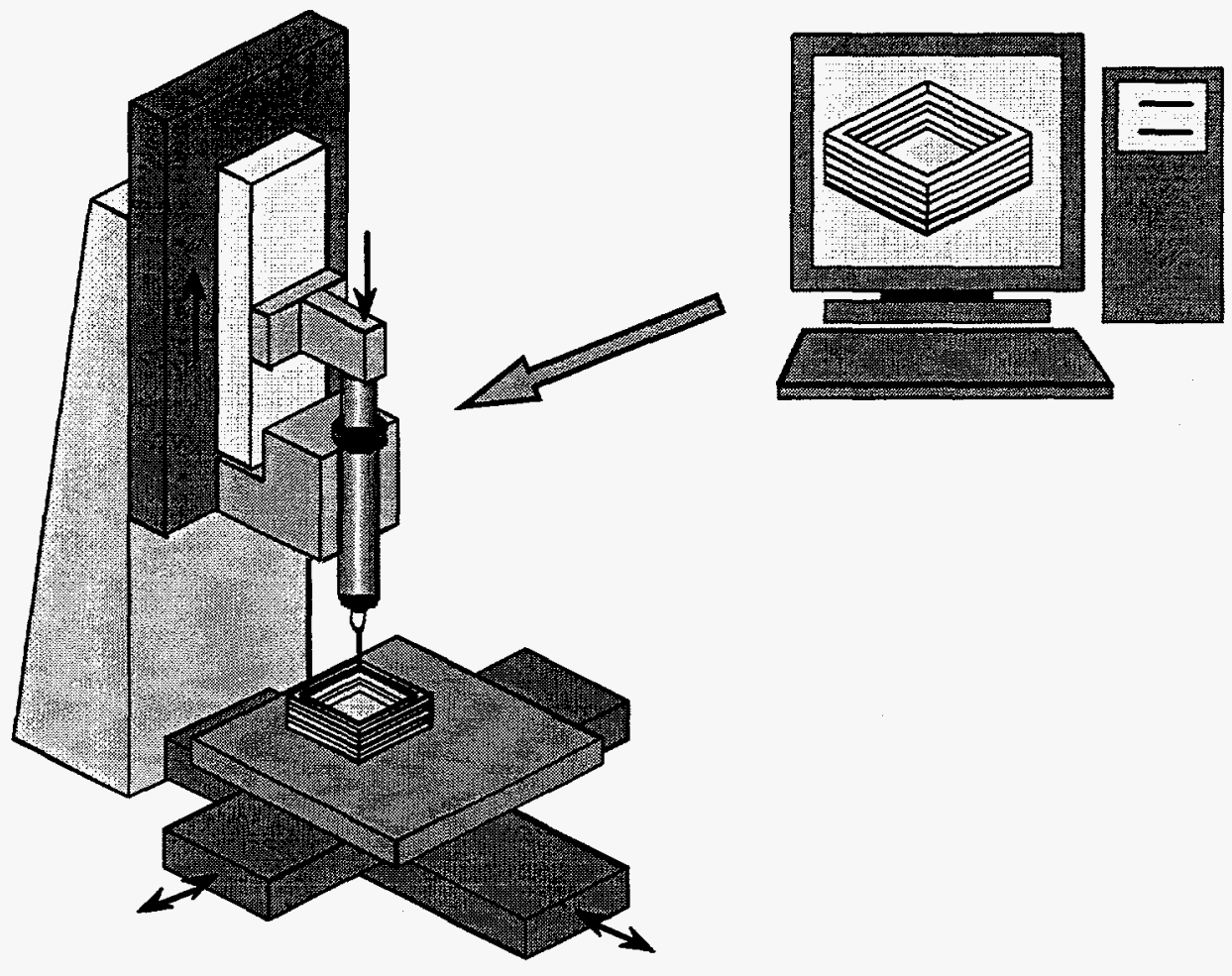

Figure 1: Robocasting: Computer Controlled Extrusion of Aqueous Slurries
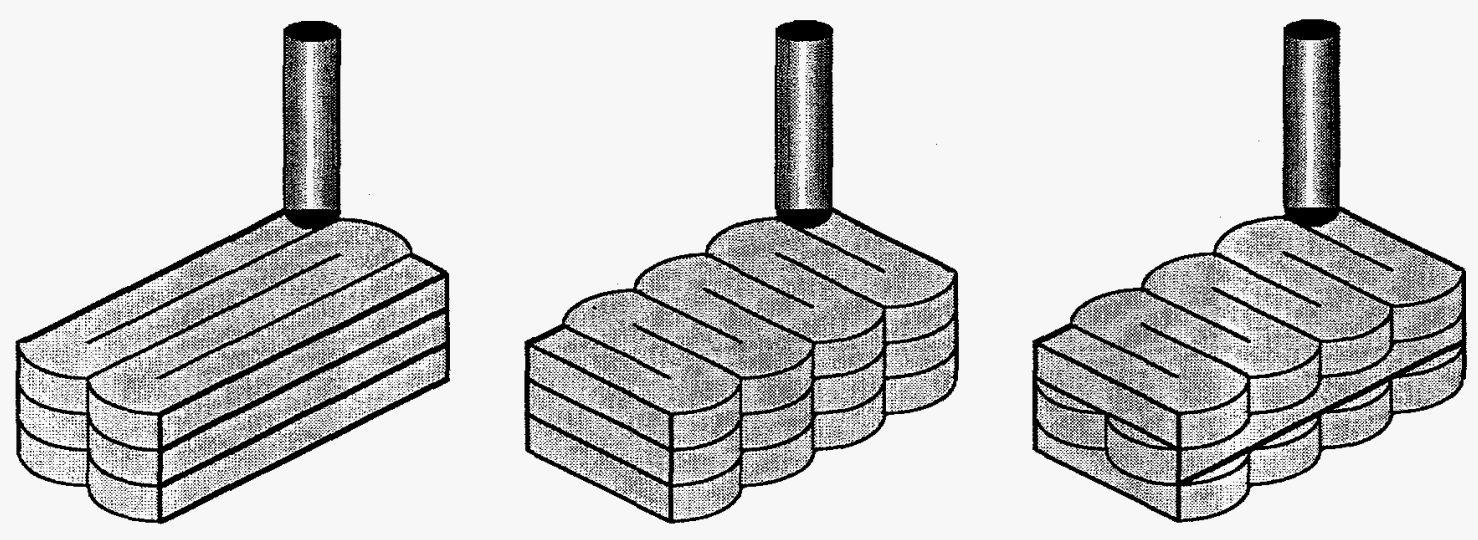

Figure 2: Robocasting build patterns; lengthwise, widthwise, and crosshatch. 


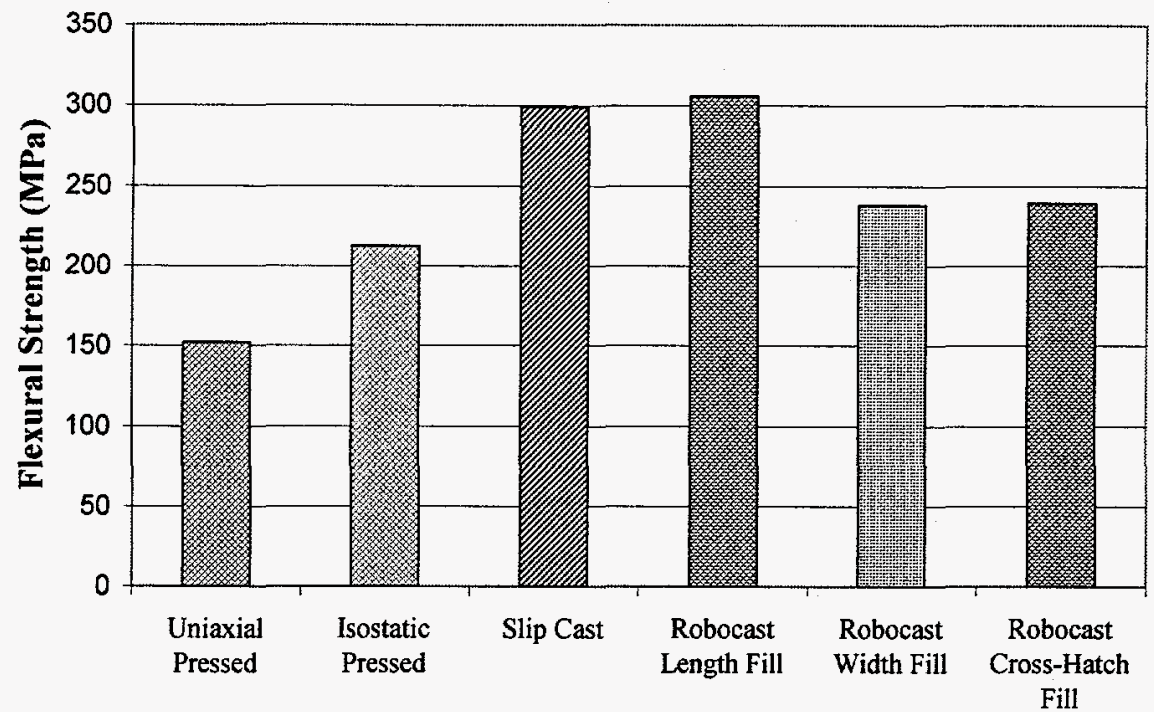

Processing Method

Figure 3: Flexural strength of alumina for various processing methods (Mil-Std-1942b).

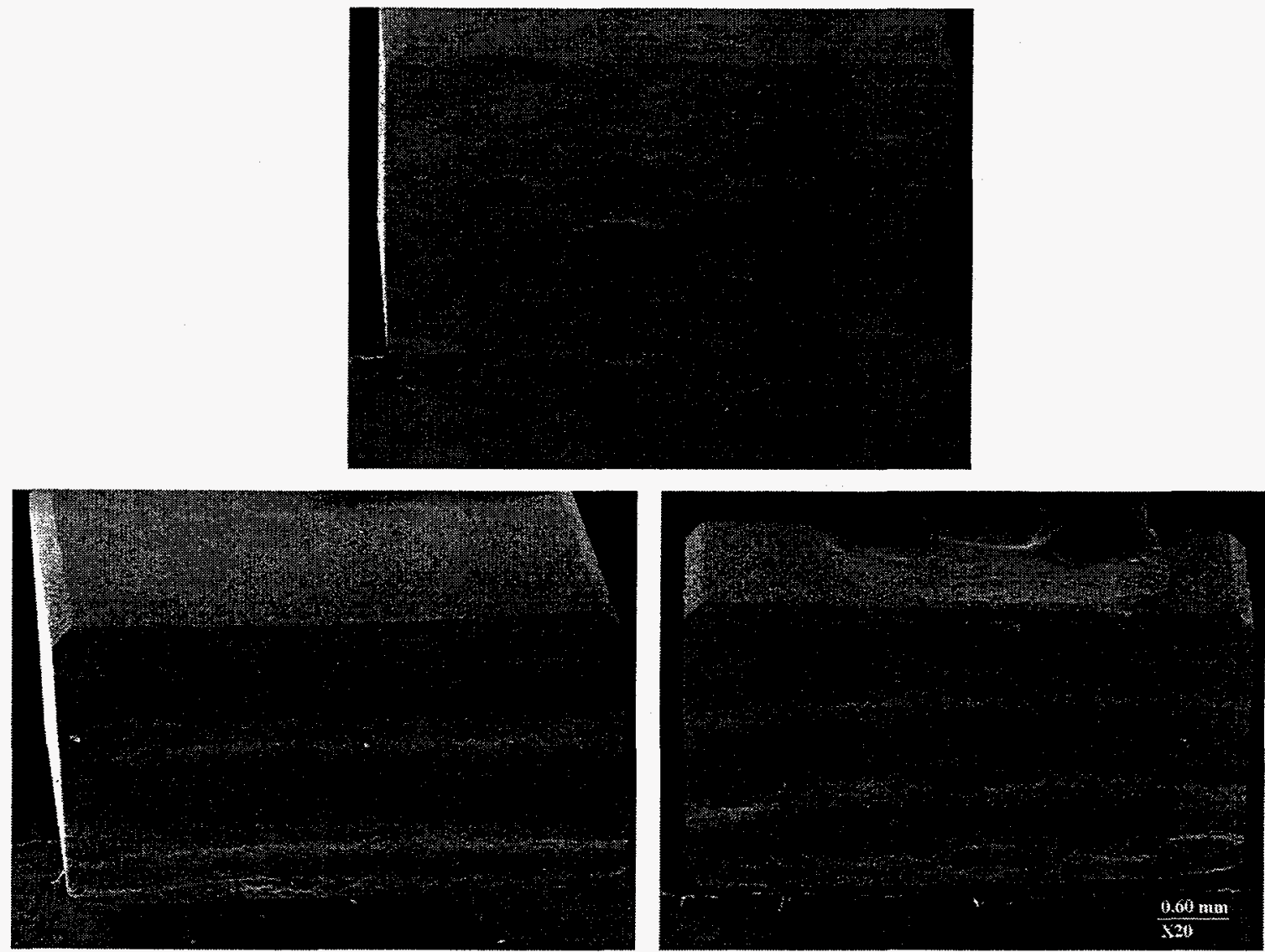

Figure 4: Cross-Sections of the Different Build Patterns of Robocast Alumina Showing Texture. 

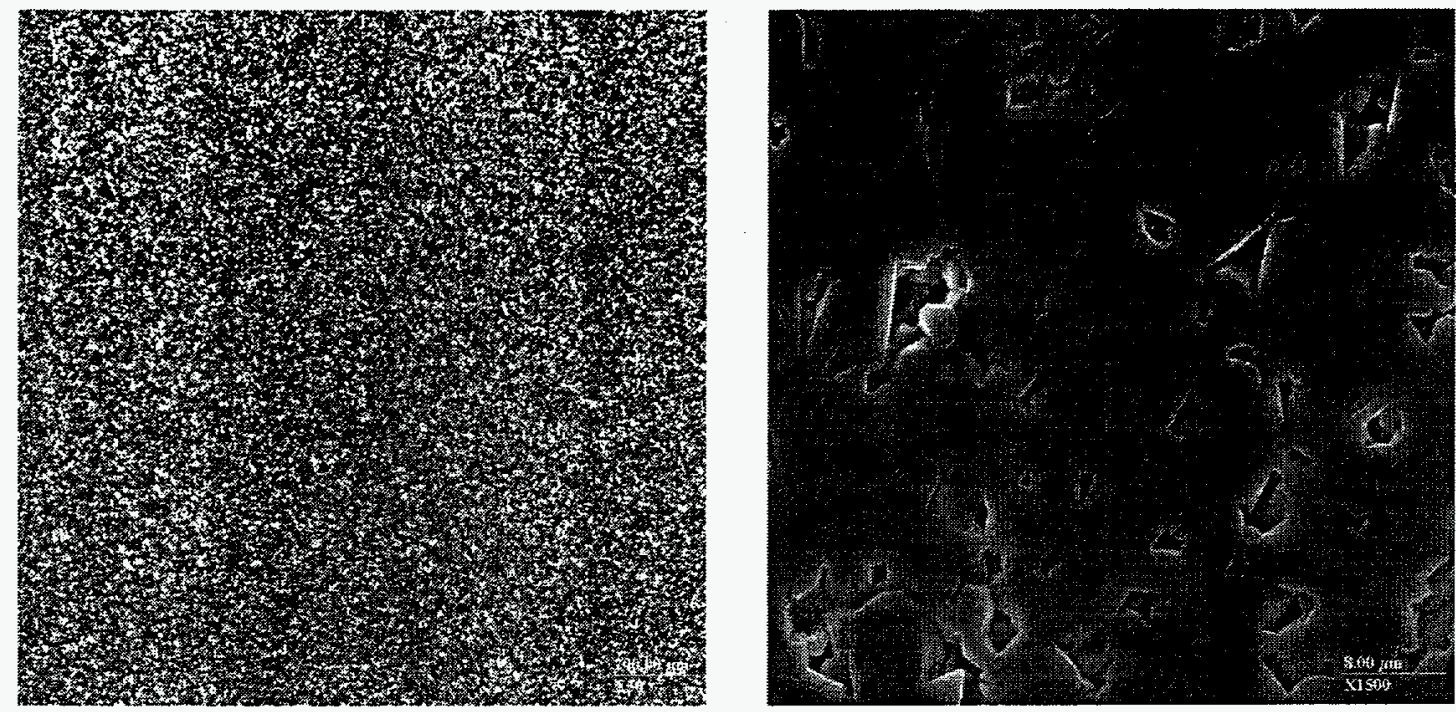

Figure 5: SEM Micrographs of Cross-Sectioned Robocast Alumina Showing the Layered Pattern at (left to right) Low and High Magnifications. 